\title{
Calculating sediment trapping efficiencies for reservoirs in tropical settings: A case study from the Burdekin Falls Dam, NE Australia
}

\author{
Stephen E. Lewis, ${ }^{1}$ Zoë T. Bainbridge, ${ }^{1}$ Petra M. Kuhnert, ${ }^{2}$ Bradford S. Sherman, ${ }^{3}$ \\ Brent Henderson, ${ }^{4}$ Cameron Dougall, ${ }^{5}$ Michelle Cooper, ${ }^{6}$ and Jon E. Brodie ${ }^{1}$ \\ Received 9 September 2012; revised 19 December 2012; accepted 21 January 2013; published 25 February 2013.
}

[1] The Brune and Churchill curves have long been used to predict sediment trapping efficiencies for reservoirs in the USA which typically experience winter and springdominant runoff. Their suitability for reservoirs receiving highly variable summer-dominant inflows has not previously been evaluated. This study compares sediment trapping efficiency (TE) data with the predictions of the two established curves for the Burdekin Falls Dam, a large reservoir in northern tropical Australia which receives highly variable summer-dominant runoff. The measured TE of the reservoir ranged between $50 \%$ and $85 \%$ and was considerably less than estimates using the Brune and Churchill curves over the 5 year study period. We modified the original equations so that daily trapping can be calculated and weighted based on daily flow volumes. This modification better accounts for shorter residence times experienced by such systems characterized by relatively high intraannual flow variability. The modification to the Churchill equation reasonably predicted sediment TEs for the Burdekin Dam for four of the five monitored years and over the whole monitoring period. We identified four key sediment particle classes: (1) $<0.5 \mu \mathrm{m}$ which exclusively passes over the dam spillway; (2) $0.5-5.0 \mu \mathrm{m}$ which, on average, $50 \%$ is trapped in the reservoir; (3) 5.0-30 $\mu \mathrm{m}$ most (75\%) of which is trapped; and (4) $>30 \mu \mathrm{m}$ which is almost totally $(95 \%)$ trapped in the dam reservoir. We show that the modification to the Churchill equation has broader application to predict reservoir TE provided that daily flow data are available.

Citation: Lewis, S. E., Z. T. Bainbridge, P. M. Kuhnert, B. S. Sherman, B. Henderson, C. Dougall, M. Cooper, and J. E. Brodie (2013), Calculating sediment trapping efficiencies for reservoirs in tropical settings: A case study from the Burdekin Falls Dam, NE Australia, Water Resour. Res., 49, doi:10.1002/wrcr.20117.

\section{Introduction}

[2] The anthropogenic disturbance of the water cycle through reservoir construction, agriculture, deforestation, and urbanization has caused considerable changes in the fluxes of freshwater, sediment, and nutrients to the ocean [see Vörösmarty and Sahagian, 2000; Syvitski et al., 2005;

\footnotetext{
All Supporting Information may be found in the online version of this article.

${ }^{1}$ Catchment to Reef Research Group, TropWATER, James Cook University, Townsville, Queensland, Australia.

${ }^{2}$ CSIRO Mathematics, Informatics and Statistics, Glen Osmond, South Australia, Australia.

${ }^{3}$ CSIRO Land and Water, Canberra, ACT, Australia.

${ }^{4}$ CSIRO Mathematics, Informatics and Statistics, Canberra, ACT, Australia.

${ }^{5}$ Department of Natural Resources and Mines, Bundaberg, Queensland, Australia.

${ }^{6}$ Minerals and Natural Hazards Division, Geoscience Australia, Canberra, ACT, Australia.

Corresponding author: S. E. Lewis, Catchment to Reef Research Group, TropWATER, James Cook University, ATSIP Bldg. DB145, Townsville, Queensland 4811, Australia. (stephen.lewis@jcu.edu.au)

(C)2013. American Geophysical Union. All Rights Reserved. 0043-1397/13/10.1002/wrcr.20117
}

Horowitz et al., 2008]. These changes have many geomorphological and ecological consequences for downstream environments. Increasing sediment and nutrient loads have been linked to, for example, decline in coral cover and seagrass abundance [e.g., Fabricius, 2005; Restrepo et al., 2006], while reductions in sediment and nutrient loads have caused coastal erosion and the collapse of inshore fisheries [reviewed in Syvitski, 2003; Syvitski et al., 2005]. Models have predicted that $3-5 \mathrm{Gt}$ of sediment is trapped by reservoirs annually compared to a total global sediment flux of 20 Gt per year [Syvitski, 2003; Vörösmarty et al., 2003; Syvitski et al., 2005]. It is evident that large increases or reductions in sediment and associated nutrient loads disturb the dynamic balance of coastlines and delicate ecosystems.

[3] Accurate quantification of sediment trapping in reservoirs improves the estimates of river sediment export, allows the useful life of reservoirs to be determined, and provides insights into sediment transport and dynamics of watersheds. However, several of the empirical equations to estimate reservoir trapping efficiency (TE) [e.g., Brown, 1943; Churchill, 1948; Brune, 1953; Chen, 1975] have been developed in temperate environments for normally ponded reservoirs and their use in subtropical and tropical climatic regimes is questionable. In particular, differences in the timing (i.e., implications for the stratification of reservoir) and variability of 
inflows and fluctuating water levels throughout the year in these tropical systems considerably influence the residence time of such reservoirs which cannot be accounted by the empirical equations in their current form. Therefore, a new approach is required to provide relatively fast and accurate estimates of sediment TE for the large number of reservoirs situated in tropical settings.

[4] The Burdekin Falls Dam (BFD) is located in the Dry Tropics of north-east Australia and receives highly variable interannual and intraannual inflows which are concentrated in the wet season months (December to April). Estimates of the TE of the BFD vary greatly with the common empirical equations [e.g., Brune, 1953; Heinemann, 1981] suggesting that $80-90 \%$ of incoming sediment is trapped [Prosser et al., 2002; McKergow et al., 2005] while field studies suggest that negligible sediment (but not quantified) is retained in the reservoir [Faithful and Griffiths, 2000]. The BFD regulates $88 \%$ of the Burdekin River watershed which, in turn, is the largest contributor of suspended sediment to the Great Barrier Reef (GBR) [Kroon et al., 2012]. Thus, accurate quantification of the sediment TE of the BFD is important to prioritize remedial works to reduce sediment delivery from the Burdekin River. Moreover, the latest modeling framework for the GBR watershed (Source Catchments) has increased temporal resolution to a daily time step [Carroll et al., 2012] and so there is a need for a simple model to reliably predict daily reservoir TEs.

[5] The key objective of this research is to evaluate whether the Brune [1953], Churchill [1948], or Chen [1975] methods can reliably estimate sediment trapping for the BFD reservoir over five monitored water years. We quantify the proportion of sediment loads and particle size fractions delivered from the four upstream watersheds and examine the implications for management of "bulk sediment" versus "size-specific" fractions as a result of our findings. We explore potential modifications that can be made to the Brune and Churchill equations to improve reservoir trapping predictions for the BFD. Finally, we examine whether these modifications can be applied to other reservoirs where adequate data are available.

\section{Empirical Trapping Efficiency Equations}

[6] TE estimators calculate the percentage of the inflowing sediment mass that remains permanently in the reservoir. Several methods for calculating TE exist in the literature [Borland, 1971; Heinemann, 1984; Chen, 1975; Verstraeten and Poesen, 2000; Espinosa-Villegas and Schnoor, 2009]. Historically, the two most common approaches are (1) the relationship developed by Brune [1953] and (2) the sedimentation index curve of Churchill [1948]. The Brune [1953] curve, which equates "capacity to inflow ratio", requires little input data, is simple to apply, and has been widely adopted to estimate reservoir TE. In contrast, the Churchill [1948] curve incorporates both water retention period (hereafter referred to as residence time) and flow velocity to calculate a "sedimentation index" for the reservoir. The Churchill [1948] index produces two curves that describe TEs for "locally derived" sediment upstream of the reservoir and for "overflow sediments" that have passed through other upstream reservoirs. The data sets used to formulate both the Brune [1953] and
Churchill [1948] curves are based on measured TEs from "normally ponded" reservoirs. These reservoirs are located in temperate climatic regimes that receive more regular inflows throughout the year (i.e., snowmelt influence) compared to tropical and subtropical rivers such as those of the GBR watershed which are characterized by highly variable seasonal flows. Importantly, these empirical equations specify the use of "average annual inflow" and do not account for watersheds with highly variable intraannual inflows. A seemingly more comprehensive technique for calculating reservoir TE was developed by Chen [1975]. This technique incorporates flow velocity and particle size data using Camp's [1946] settling velocity equations to predict TE for each particle size class.

[7] In this study, we examine three commonly used methods for calculating TE statistics, the Brune [1953], Churchill [1948], and Chen [1975] methods (hereafter referred to as Brune, Churchill, and Chen, respectively), and apply them to the BFD. The Brune and Churchill curves were developed empirically using measured TEs of reservoirs whereas the Chen relations reflect essentially a theoretical analysis of particle settling. We investigate modifications to the Brune and Churchill equations so they may produce daily trapping estimates and assess their suitability for calculating TE for reservoirs with much shorter residence times due to high intraannual flow variability and stratified water columns which have not previously been accounted for.

[8] The Brune curve $\left(\mathrm{TE}_{\mathrm{BR}}\right)$ as given by Heinemann [1981] is

$$
\mathrm{TE}_{\mathrm{BR}}=100 \times\left(\frac{\tau}{0.012+1.02}\right),
$$

where $\tau=V / Q$ is the residence time (in years), $V$ is the reservoir volume $\left(\mathrm{m}^{3}\right)$ at capacity and $Q$ is the mean annual inflow $\left(\mathrm{m}^{3} \mathrm{yr}^{-1}\right)$.

[9] The Churchill curve $\left(\mathrm{TE}_{\mathrm{CH}}\right)$ is

$$
\mathrm{TE}_{\mathrm{CH}}=112-800 \times\left(\frac{9.61 \times 10^{6} \tau}{u}\right)^{-0.2}
$$

where the constant, $9.61 \times 10^{6}$ represents a conversion from years to seconds and meters to feet to meet the requirements of the Espinosa-Villegas and Schnoor [2009] equation and $u$ is the mean annual velocity of the inflow (in $\mathrm{ms}^{-1}$ ) which is expressed as

$$
u=\frac{3.17 \times 10^{-8} Q}{A},
$$

where the constant, $3.17 \times 10^{-8}$ represents a conversion between inflow per year to inflow per second and $A$ is the surface area of the reservoir (in $\mathrm{m}^{2}$ ) which is calculated by $V / L$ ( $L=$ the length of the reservoir measured from the dam wall to the most upstream impounded water at dam capacity in $\mathrm{m}$ ).

[10] Chen provides the upper and lower bounds for the TE of a basin. The highest efficiency occurs when the water column is completely still and the particles sink uniformly. 
In this case, the reservoir is stratified where Chen's equation $\left(\mathrm{TE}_{\mathrm{CN} \text { (stratified) }}\right)$ is

$$
\mathrm{TE}_{\mathrm{CN}(\text { stratified })}=w A / Q,
$$

where $w$ is the settling velocity of the different particle sizes [in $\mathrm{m} \mathrm{yr}^{-1}$ : see Table 2 in Chen, 1975].

[11] The lowest TE occurs for a continuously mixing, i.e., actively turbulent, water column and is given by

$$
\mathrm{TE}_{\mathrm{CH}(\text { mixed })}=-\exp (-w A / Q) .
$$

[12] We note here that the lowest efficiency case is analogous to an inflow entering a well-mixed reservoir, a condition that is likely to occur in winter and early spring assuming ice-free conditions. The highest efficiency case (equation (4)) would be similar to an inflow entering a strongly stratified reservoir, i.e., late spring-early autumn, and assuming no actively mixing surface layer. Tropical and subtropical reservoirs, such as the BFD, often receive $>90 \%$ of their inflow over 1-2 months during the summer wet season when reservoir thermal stratification is the strongest. In addition, the seasonal inflow variability is much greater in the tropics compared to the North American streams upon which the Brune and Churchill relations are based. Finally, the North American inflows tend to occur in winter/spring when reservoir stratification is relatively weaker. As a consequence, the residence times for the North American streams are relatively greater than those in tropical environments (see discussion).

[13] Modifications to the Brune and Churchill equations were made so that daily TEs can be calculated to account for the reduction in residence times experienced by the $\mathrm{BFD}$. The daily residence time, $\tau^{*}$, is computed as

$$
\tau^{*}=\frac{V}{Q_{i}} / 365
$$

where $Q_{i}$ is the inflow volume $\left(\mathrm{m}^{3}\right)$ on day $i$.

[14] The daily TEs, $\mathrm{TE}_{\mathrm{BR}, i}$, and $\mathrm{TE}_{\mathrm{CH}, i}$, are computed by substituting (6) for $\tau$ in equations (1) and (2). Because the majority of river sediment is transported during higher inflow periods, the daily TEs are then weighted based on daily flow volumes. The new set of equations for the Brune and Churchill methods, $\mathrm{TE}_{\mathrm{BR}^{*}}$ and $\mathrm{TE}_{\mathrm{CH}^{*}}$, become

$$
\begin{aligned}
\mathrm{TE}_{\mathrm{BR} *} & =\frac{\sum_{i=1}^{n} \mathrm{TE}_{\mathrm{BR}, i} Q_{i}}{\sum_{i=1}^{n} Q_{i}}, \\
\mathrm{TE}_{\mathrm{CH} *} & =\frac{\sum_{i=1}^{n} \mathrm{TE}_{\mathrm{CH}, i} Q_{i}}{\sum_{i=1}^{n} Q_{i}} .
\end{aligned}
$$

[15] We applied equations (7) and (8) for each water year (i.e., $n=$ number of days from 1 October to 30 September) and also to those periods when the BFD was spilling to calculate sediment trapping in the BFD.

[16] We also performed the calculations assuming the measured discharge downstream of the dam was equivalent to the inflow rather than adding up the three upstream gauges and also accounting for the ungauged upstream area ( $8 \%$ of the total upstream area). Considering only periods when the dam was spilling, this assumption implicitly includes contributions from direct precipitation and evaporation. TEs computed using either estimate of inflow agreed to within $2 \%$. We note that evaporation and the release of irrigation water would have significant effects on dam levels in the dry season. We estimate that annual evaporation amounts in the BFD are between $3.0 \times 10^{9}$ and $5.3 \times 10^{9}$ $\mathrm{m}^{3} \mathrm{yr}^{-1}$ based on our water budgets (although note uncertainties in flow gauge estimates) and average annual evaporation ( $\sim 2400 \mathrm{~mm} \mathrm{yr}^{-1}$ : Bureau of Meteorology [2012]; surface area of dam $=2.2 \times 10^{8} \mathrm{~m}^{2}$ ). Thus, it generally represents $<10 \%$ of the total annual average inflows to the dam (i.e., within uncertainty estimates of inflow) or $\sim 25 \%$ of the dam capacity. We note that direct precipitation into the dam averages $\sim 1.5 \times 10^{8} \mathrm{~m}^{3} \mathrm{yr}^{-1}\left[650 \mathrm{~mm} \mathrm{yr}^{-1}\right.$ : Bureau of Meteorology, 2012].

\section{Methods}

\subsection{Sample Collection}

[17] Suspended sediment samples were collected using a combination of manual and automated sampling [Lewis et al., 2009a, 2009b; supporting information] techniques over five consecutive wet seasons (2005/2006 to 2009/2010). Samples were collected from as close as practical to the stream flow gauging stations representing each major tributary upstream of the BFD (Burdekin, Cape, Belyando and Suttor Rivers) and the BFD spillway (Figure 1). A total of 868 samples were collected over the rising, peak, and falling stages of the hydrograph following significant rainfall events (Figure 2) and analyzed for total suspended solids (TSS).

[18] Previous sampling of the Burdekin River has shown that clay and silt particles $(<63 \mu \mathrm{m})$ are well mixed throughout the water column, although the sand fraction can increase towards the river bed [see Belperio, 1979; Amos et al., 2004]. Hence, our sampling method (i.e., mostly from the top $50 \mathrm{~cm}$ of the water column) adequately captures the clay and silt fractions but is likely to underestimate the coarser bed load component. We contend that this approach is suitable for the purpose of this study as very little of the sand fraction passes through the BFD [see Faithful and Griffiths, 2000; this study) and the particle size composition of sediments in grab samples collected from the reservoir floor (M. Cooper, unpublished data, 2005) is similar to that measured in the surface inflow waters (i.e., $\leq 6 \%$ sand: this study); these results suggest that the bed load fraction is largely deposited before it enters the reservoir. The TSS data collected from the autosamplers (i.e., samples from the lower to mid water column) in the 2009/2010 wet season also showed similar concentrations to those samples collected from the surface. Furthermore, the TE method of Churchill predicts the "percent of incoming silt passing through reservoir", and Chen has shown that both the Brune and Churchill methods are designed specifically to predict the trapping of silt sized particles.

\subsection{Load Calculations}

[19] Flow data from the Burdekin River at Sellheim (gauge no. 120002C), Cape River at Taemas (120302B), 


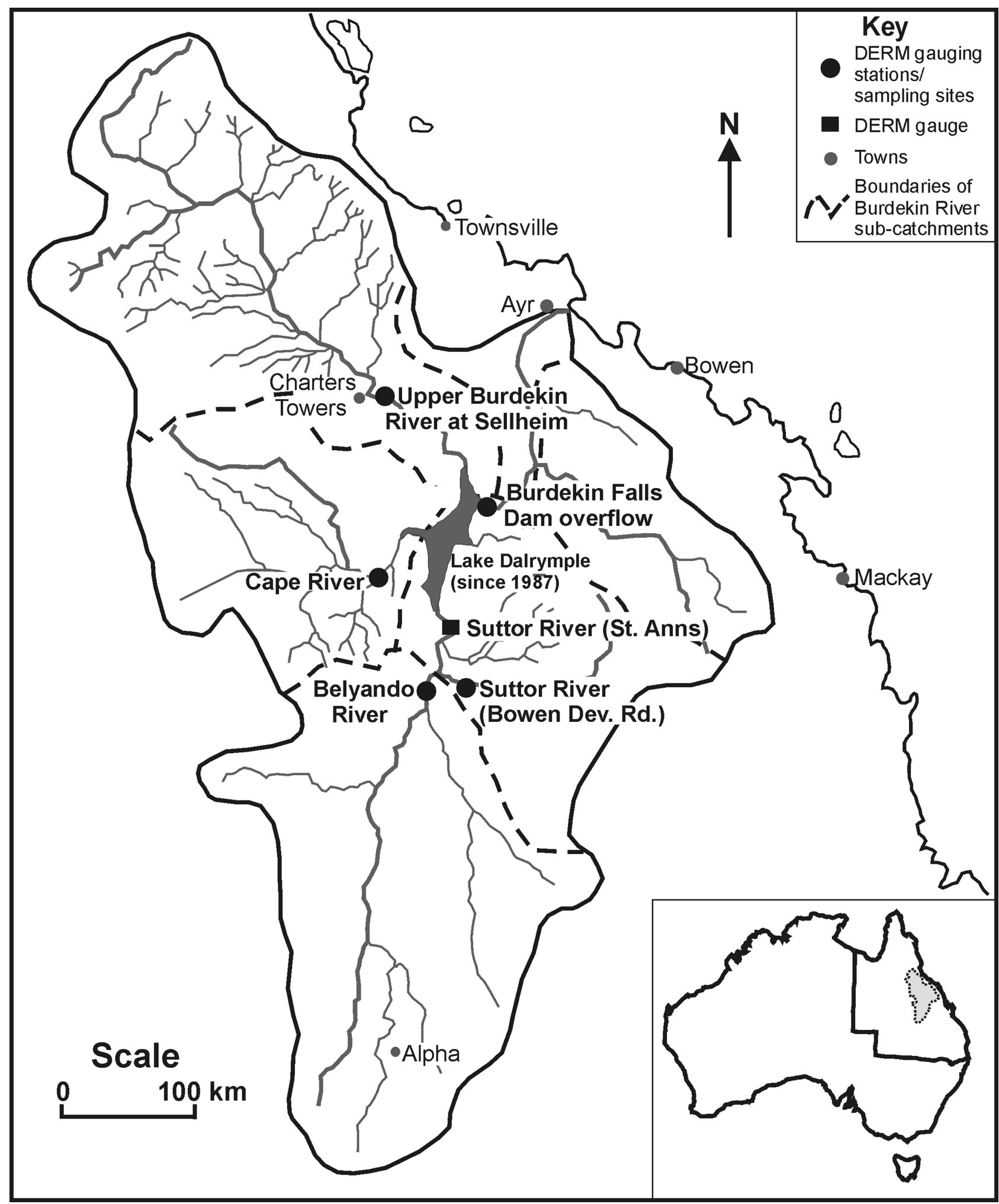

Figure 1. Map of the Burdekin River watershed, north Queensland, Australia showing sampling locations used in this study.

Belyando River at Gregory Developmental Road (120301B), Suttor River at St Anns (120303A), and the Burdekin River at Hydro Site (BFD overflow: 120015A) were used with the corresponding TSS data to calculate suspended sediment loads (Figure 2). The Suttor River at Bowen Developmental Road (120310A) gauge did not become operational until the 2006/2007 wet season and so we used the downstream Suttor River at St Anns gauge minus the Belyando River gauge 

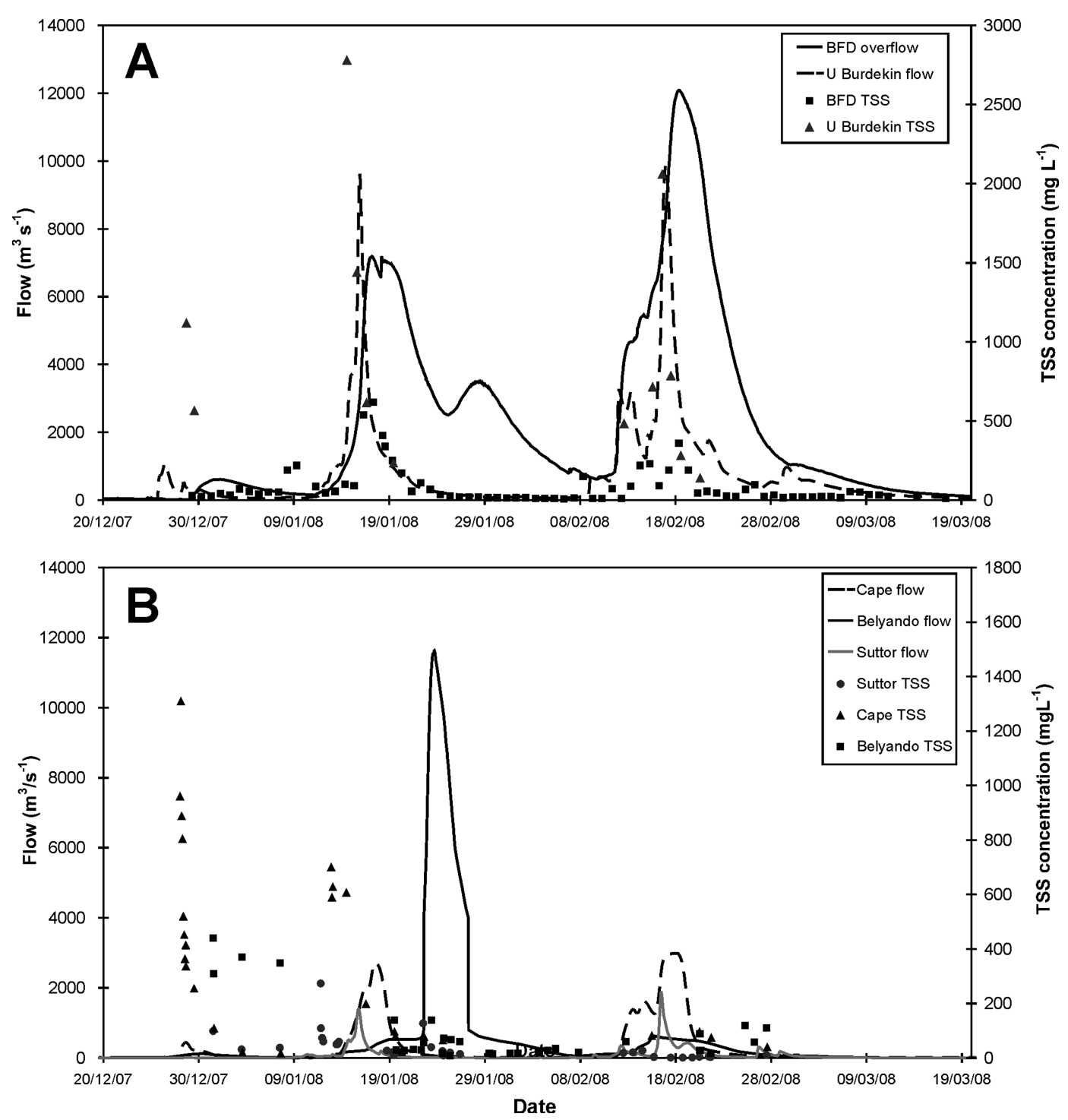

Figure 2. An example of typical flow hydrographs and total suspended sediment (TSS) concentrations for the four upstream rivers and BFD overflow for the 2007/2008 water year. (A) The upper Burdekin River consistently has the highest TSS concentrations and mostly produces the largest flows contributing to the BFD overflow. (B) The Cape, Belyando and Suttor Rivers, in comparison, generally have lower TSS concentrations (note change in scale) and have lower flows. Note the higher TSS concentrations on the rising limb of the flow and the relatively short durations (i.e., 5-10 days) of the highly variable inflows to the dam and over the dam spillway ( $\sim 30$ days).

flow data to estimate the total discharge (and thus suspended sediment load) for the Suttor River arm (Figure 1). This process assumes that the mean annual TSS concentration (MAC) for Rosetta Creek (a tributary of the Suttor River contributing to the measurement at the St Anns gauge) is identical to that measured at the Suttor River at Bowen Developmental Road.

[20] TSS loads were calculated using a regression (rating-curve) style "Loads Regression Estimator" (LRE) [Kuhnert et al., 2012]. This estimator incorporates additional predictors that account for meaningful features in the flow and concentration relationship including the concept of a "first flush", sample distribution across the flow hydrograph and the exhaustion of sediment supply and therefore TSS concentrations over the flow period ("discounted flow"), all of which improve the prediction of concentration. A particular advantage of the LRE, compared to other methods, is the ability to quantify uncertainties in the load estimates that also incorporate the errors in flow rates [Kuhnert et al., 2012]. These errors are input into the model as a coefficient of variation (CV) and represent the error due to spatial positioning of a gauge and measurement error of flow, both of which were assigned a CV of $10 \%$. We note that this method is an important distinction between our previous investigations [Lewis et al., 2009a, 2009b] which used the linear interpolation technique for load calculation and only provided a qualitative estimate of uncertainty. Moreover, the differences in the flow volumes reported in our previous work are likely related to the development of revised flow rating curves and improved flow 
validation by the Queensland Department of Natural Resources and Mines [State of Queensland, 2012]. Output from the LRE model are load estimates in tonnes and a measure of uncertainty in the estimate that can be reported as a standard deviation, a confidence interval or a CV. We report the latter in the results section of this manuscript where the loads have been rounded to two significant figures (raw outputs are presented in supporting information Tables S2-S6).

[21] Sediment trapping in the BFD was calculated using the dam inflow and overflow sediment loads (note that overflow loads include release water for irrigation) and uncertainty in the trapping estimates were calculated as follows. Let $R$ represent the ratio between the load (in tonnes) calculated at the BFD overflow $\left(L_{O}\right)$ and the load calculated at the inflow to the Dam $\left(L_{I}\right)$, such that $R=\frac{L_{0}}{L_{I}}$. Let $T$ represent the proportion of the load that is trapped, such that $T=1-R$. Then the variance for the trapping estimate can be calculated as follows and $80 \%$ confidence intervals can be calculated in the usual way.

$$
\begin{gathered}
\operatorname{Var}(T)=\operatorname{Var}(R) \\
=\operatorname{Var}\left(\frac{L_{O}}{L_{I}}\right) \\
\approx \frac{E^{2} L_{O}}{E^{2} L_{I}}\left[\frac{\operatorname{Var}\left(L_{O}\right)}{E^{2} L_{O}}+\frac{\operatorname{Var}\left(L_{I}\right)}{E^{2} L_{I}}\right]
\end{gathered}
$$

assuming independence and appealing to a well-known statistical approximation for the variance of a ratio of two random variables [Stuart and Ord, 1987].

[22] Now $\operatorname{Var}\left(L_{I}\right)=\operatorname{Var}\left(\Sigma_{s} L_{s}\right)$

$$
=\sum \operatorname{Var}\left(L_{s}\right)
$$

where $L_{s}$ represents the load at subcatchment $s$ and assuming independence

$\operatorname{Var}\left(L_{O}\right)=$ variance of load at overflow site.

$E\left[L_{O}\right]=$ estimate of load at overflow site.

$E\left[L_{I}\right]=$ estimate of load at inflow site.

\subsection{Particle Size Load Calculations}

[23] We used a three-step process to calculate loads for each of the 83 particle bin sizes for the upstream rivers and BFD overflow to examine the trapping of specific particle sizes in the BFD and to quantify their watershed sources. First, we used linear interpolation to calculate daily particle size distribution on days where no sample was collected provided that data existed before and after that interpolated day. This interpolation was conducted on the particle size data from each river and for the BFD overflow. Second, we multiplied the daily suspended sediment load (calculated by the LRE) by the corresponding particle size distribution data. These daily particle size distribution load data were then summed for each river and BFD overflow for four individual monitored water years (2005/2006 to 2008/ 2009). Third, the particle size distribution load data were extrapolated to account for the period outside of the sample collection to match the total suspended sediment load calculated for each river and BFD overflow over the monitored water years. While the data provide important insights into the movement of different particle size fractions through the dam, the sparse collection of samples for the upstream rivers prohibits the calculation of a comprehensive mass balance.

\section{Results}

\subsection{Flow Variability}

[24] The 5 year monitoring program captured considerable variability in flow entering the BFD reservoir from the upstream watershed, ranging from small flows in 2005/06 (total inflow $3.4 \times 10^{9} \mathrm{~m}^{3}$ ) to very large flows in 2007/ $2008\left(19.2 \times 10^{9} \mathrm{~m}^{3}\right)$ and 2008/2009 $\left(25.6 \times 10^{9} \mathrm{~m}^{3}\right)$ (Tables S2-S6, supporting information) compared to the mean annual inflow of $7.2 \times 10^{9} \mathrm{~m}^{3}$ for the period 19872010. In particular, the flows in the Belyando and Suttor Rivers in 2007/2008 and in the Burdekin River in 2008/ 2009 were exceptionally large and likely represent 1 in 30 to 1 in 50 year events. Each of the contributing tributary watershed areas received widespread rainfall in at least three of the 5 years which caused appreciable flows and so our data set has complete coverage of available land-type and geological sources in the watershed that influence the characteristics of the suspended sediments that enter the BFD reservoir.

\subsection{Suspended Sediment Concentrations}

[25] TSS concentrations were highest on the rising/peak stages of the flow hydrographs in all watersheds (Figure 2). In the very large event flows of 2007/2008, TSS concentrations were considerably lower (mean annual concentration of $50-120 \mathrm{~m} \mathrm{~L} \mathrm{~L}^{-1}$ ) in the Belyando and Suttor Rivers, than for other years $\left(180-650 \mathrm{mg} \mathrm{L}^{-1}\right)$. This result suggests that sediment exhaustion/dilution or settling of sediments due to the overbank flows occurred during the 2007/2008 wet season. In comparison, the TSS concentrations in the upper Burdekin (mean annual concentration of $680-800 \mathrm{mg} \mathrm{L}^{-1}$ ) and Cape Rivers (205-360 mg L ${ }^{-1}$ ) were similar over all five wet seasons despite considerable variability in total discharge (see Tables S2-S6 in supporting information).

\subsection{Sediment Budgets and Reservoir Trapping}

[26] The sediment budgets constructed over the five sampled water years suggest that the BFD trapped $85 \%$ $(80 \%$ CI $=79-91)$ of suspended sediment in the $2005 / 2006$ water year, $56 \%(80 \% \mathrm{CI}=40-71)$ in $2006 / 07,50 \%(80 \%$ $\mathrm{CI}=36-64)$ in $2007 / 2008,70 \%(80 \% \mathrm{CI}=58-81)$ in $2008 /$ 2009 and $82 \%(80 \% \mathrm{CI}=77-86)$ in 2009/2010 (Table 1). TSS loads delivered to the BFD were predominantly sourced from the upper Burdekin River which contributed $70 \%-94 \%$ of the total sediment load delivered to the dam over the five sampled water years, with the other watersheds contributing $\leq 11 \%$ each (see Tables S2-S6 in supporting information).

\subsection{Comparisons to Empirical Equations}

[27] The measured data from the BFD do not agree with the standard Brune or Churchill curves used to predict reservoir trapping (Figure 3). These equations overestimate trapping in the BFD by as much as $26 \%$ while the Chen equations that incorporate particle size also overestimate trapping by as much as $28 \%$ (Table 2). The modifications 
Table 1. Summary of Sediment Loads Received by the Burdekin Falls Dam and Sediment Loads Passing Over the Dam Spillway during the Five Monitored Water Years ${ }^{\mathrm{a}}$

\begin{tabular}{|c|c|c|c|c|c|c|c|c|c|c|}
\hline Year & $2005 / 2006$ & $\mathrm{CV}$ & $2006 / 2007$ & $\mathrm{CV}$ & $2007 / 2008$ & $\mathrm{CV}$ & $2008 / 2009$ & $\mathrm{CV}$ & $2009 / 2010$ & $\mathrm{CV}$ \\
\hline Dam overflow discharge $\left(\mathrm{m}^{3}\right)$ & $2.1 \times 10^{9}$ & & $6.5 \times 10^{9}$ & & $18.0 \times 10^{9}$ & & $25.0 \times 10^{9}$ & & $5.5 \times 10^{9}$ & \\
\hline Upper Burdekin sediment load (tonnes) & $2,100,000$ & $14 \%$ & $3,100,000$ & $13 \%$ & $4,700,000$ & $10 \%$ & $15,000,000$ & $14 \%$ & $1,700,000$ & $12 \%$ \\
\hline Cape River sediment load (tonnes) & 34,000 & $15 \%$ & 190,000 & $12 \%$ & 500,000 & $11 \%$ & 470,000 & $10 \%$ & 160,000 & $6 \%$ \\
\hline Belyando River sediment load (tonnes) & 180,000 & $17 \%$ & 130,000 & $26 \%$ & 210,000 & $13 \%$ & 110,000 & $11 \%$ & 160,000 & $8 \%$ \\
\hline Suttor River sediment load (tonnes) & 96,000 & $19 \%$ & 100,000 & $10 \%$ & 710,000 & $13 \%$ & 140,000 & $10 \%$ & 220,000 & $7 \%$ \\
\hline Other estimated sediment load (tonnes) b $^{\mathrm{b}}$ & 10,000 & & 360,000 & & 150,000 & & 300,000 & & 200,000 & \\
\hline Sediment load inflow waters (tonnes) & $2,500,000$ & $12 \%$ & $3,900,000$ & $11 \%$ & $6,200,000$ & $8 \%$ & $16,000,000$ & $13 \%$ & $2,500,000$ & $9 \%$ \\
\hline Sediment load overflow waters (tonnes) & 370,000 & $28 \%$ & $1,700,000$ & $25 \%$ & $3,100,000$ & $21 \%$ & $4,900,000$ & $27 \%$ & 450,000 & $16 \%$ \\
\hline Sediment trapping (\%) & \multicolumn{2}{|c|}{$85(79-91)$} & \multicolumn{2}{|c|}{$56(40-71)$} & \multicolumn{2}{|c|}{$50(36-64)$} & \multicolumn{2}{|c|}{$70(58-81)$} & \multicolumn{2}{|c|}{$82(77-86)$} \\
\hline
\end{tabular}

${ }^{\text {a}}$ Each load estimate in tonnes is accompanied by the $\mathrm{CV}$ as a measure of uncertainty. Sediment trapping estimates are presented as percentages accompanied with conservative $80 \%$ confidence intervals.

${ }^{\mathrm{b}}$ Estimated loads for the ungauged catchment area above the dam.
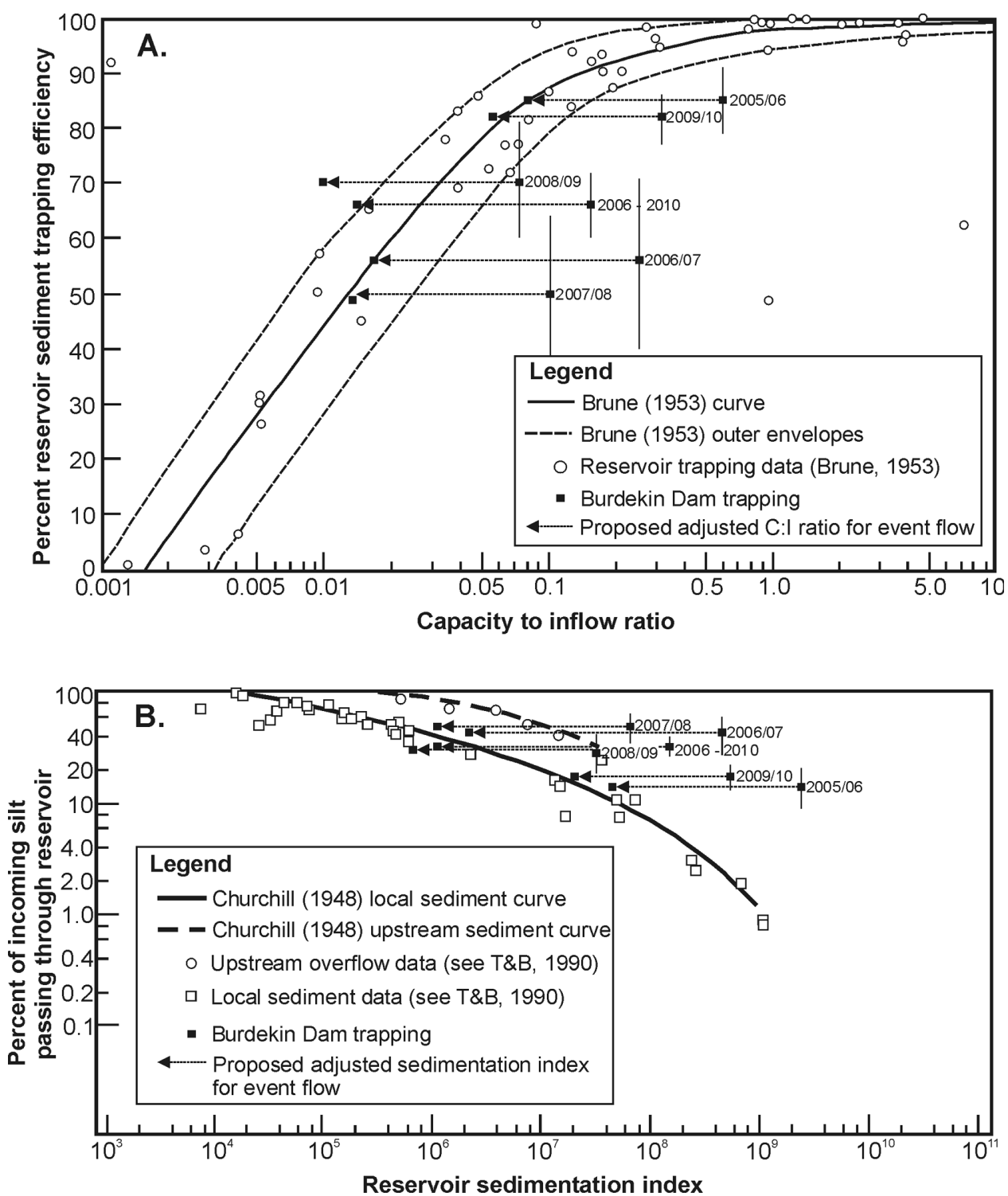

Figure 3. (A) The Brune (1953) and (B) Churchill (1948) curves used to predict the TEs of reservoirs with measured data (and associated error) from the Burdekin Falls Dam overlaid. Also shown are the results obtained when the equations were modified to account for the highly seasonal event flows from the Burdekin River (using the daily overflow calculations only in Table 2 ). $T \& B=$ Trimble and Bube (1990). 
Table 2. Summary of TEs Estimated for the Burdekin Falls Dam ${ }^{\mathrm{a}}$

\begin{tabular}{|c|c|c|c|c|c|c|}
\hline Year & $2005 / 2006$ & $2006 / 2007$ & $2007 / 2008$ & $2008 / 2009$ & $2009 / 2010$ & $2006-2010$ \\
\hline Measured sediment trapping $(\%)$ & 85 (79-91) & $56(40-71)$ & $50(36-64)$ & $70(58-81)$ & $82(77-86)$ & $66(60-72)$ \\
\hline Intraannual flow CV & 1.83 & 2.76 & 2.18 & 2.51 & 2.12 & 2.30 \\
\hline Brune [1953]—std technique & $97 \%$ & $94 \%$ & $88 \%$ & $85 \%$ & $95 \%$ & $91 \%$ \\
\hline Churchill $[1948]$ — std technique & $100 \%$ & $97 \%$ & $90 \%$ & $87 \%$ & $98 \%$ & $94 \%$ \\
\hline Chen [1975] mixed & $97 \%$ & $94 \%$ & $89 \%$ & $93 \%$ & N/A & $\mathrm{N} / \mathrm{A}$ \\
\hline Chen [1975] stratified & $99 \%$ & $96 \%$ & $92 \%$ & $97 \%$ & N/A & N/A \\
\hline Brune-daily adjustment & $90 \%$ & $62 \%$ & $\mathbf{5 3} \%$ & $45 \%$ & $82 \%$ & $55 \%$ \\
\hline Brune - daily event overflow only & $\mathbf{8 5} \%$ & $56 \%$ & $\mathbf{5 1} \%$ & $44 \%$ & $80 \%$ & $52 \%$ \\
\hline Churchill_-daily event overflow only & $89 \%$ & $65 \%$ & $60 \%$ & $52 \%$ & $84 \%$ & $60 \%$ \\
\hline
\end{tabular}

${ }^{\mathrm{a}}$ The numbers in bold show the TE calculations that lie within the estimated $80 \%$ confidence intervals.

to the Brune and Churchill equations that calculate daily trapping and weight daily flow volumes over the water year greatly improve the trapping estimates for the BFD. Although the modified Brune equation agreed with measured trapping (within the $80 \%$ confidence intervals) for the individual 2005/2006, 2006/2007, 2007/2008, and 2009/ 2010 water years, it did not accurately predict trapping for the combined 5 year period. In contrast, the modified Churchill equation predicted TE to within $80 \%$ confidence intervals over the 5 year period and predicted annual trapping accurately for the 2006/2007, 2007/2008, and 2009/ 2010 water years. The predictions of the modified Churchill equation improve further when the period of the dam overflow is considered exclusively in which case it predicts the 2005/2006, 2006/2007, 2007/2008, and 2009/2010 water years within the confidence intervals as well as the TE over the 5 year period. While the same application of the modified Brune equation also predicted the same individual water years, it did not predict TE over the whole 5 year period (Table 2).

\subsection{Particle Size Distribution}

[28] The particle size data for the BFD overflow display a distinctive bimodal distribution. The finer distribution contains particles between $0.04 \mu \mathrm{m}$ and $0.60 \mu \mathrm{m}$ with a peak at $0.20 \mu \mathrm{m}$, while the coarser and more dominant fraction ranged between 1.0 and $30 \mu \mathrm{m}$ with a peak centered at $4.5 \mu \mathrm{m}$ (Figure 4A). Bimodal distributions were also characteristic of the four upstream rivers. Only the particles in the coarser distribution fraction were trapped in the BFD reservoir. The trapped sediments predominantly ranged in size between 1.0 and $200 \mu \mathrm{m}$ with a peak at $12 \mu \mathrm{m}$ (Figure 4A). The particle size fractions for the inflow sediments over the monitored years are composed of $27 \%$ clay $(<4$ $\mu \mathrm{m}), 67 \%$ silt $(4-63 \mu \mathrm{m})$, and $6 \%$ sand $(>63 \mu \mathrm{m})$. In comparison, the overflow fractions consist of $52 \%$ clay, $47 \%$ silt, and $1 \%$ sand. We note that the lack of samples collected from the upstream catchments for certain water years has resulted in the mass balance discrepancy apparent for the particles $<1 \mu \mathrm{m}$ (Figure 4A).

[29] The particle size distribution load data suggest that four key fractions are important in transportation through the BFD (Figure 4B). The size fraction $<0.5 \mu \mathrm{m}$ was not trapped by the BFD and was predominantly delivered from the Suttor River $(\sim 50 \%)$ with the three other rivers contributing $15 \%-20 \%$ each of this fraction. On average, $50 \%$ of the $0.5-5.0 \mu \mathrm{m}$ size fraction was trapped in the BFD reservoir which was largely delivered from the upper Burdekin River $(87 \%)$. The $5.0-30 \mu \mathrm{m}$ size fraction was mostly trapped $(\sim 75 \%)$ by the BFD and was predominantly sourced from the upper Burdekin River (91\%). Finally, the size fraction $>30 \mu \mathrm{m}$ was almost totally trapped by the BFD $(>95 \%)$ and this fraction was again mainly carried from the upper Burdekin River (95\%).

\section{Discussion}

[30] The results of this study show that the vast majority (70-94\%) of the suspended sediment load delivered to the BFD is derived from the upper Burdekin River arm. This finding supports the results of Cooper et al.'s [2006] trace element and isotopic tracing study which found that bottom sediments within Lake Dalrymple were sourced to this tributary. Therefore, any management intended to reduce bulk suspended sediment delivery (i.e., all size fractions) to the dam should focus remedial efforts on the upper Burdekin River watershed.

[31] Our data suggest that the two most commonly used methods to predict reservoir TEs, the Brune and Churchill equations [e.g., Verstraeten and Poesen, 2000], considerably overestimate trapping in the BFD. These curves have been developed for "normally ponded" reservoirs which experience relatively regular flows throughout the water year (see later). Furthermore, the Chen equations, which incorporate particle settling of different size fractions and consider both mixed and stratified systems, also considerably overestimate sediment trapping in the BFD (Table 2).

[32] There are several potential reasons, related to water transit time and sediment sinking velocity, that make the Brune, Churchill and Chen relationships not reliably predict sediment trapping in the BFD. These include (1) differences in dam stratification; (2) variability of the inflows; and (3) particle size, each of which is discussed below.

[33] The BFD receives most of its inflow during the summer period when the water column is temperature stratified [Chudek et al., 1998; Faithful and Griffiths, 2000]. Under such conditions inflows with similar temperatures, lower ionic strength and higher TSS concentrations than the dam resident water, flow through either the surface layer or metalimnion [see Faithful and Griffiths, 2000] as an interflow. As such, the inflow waters experience a shorter travel time through the reservoir than would be the case were the 

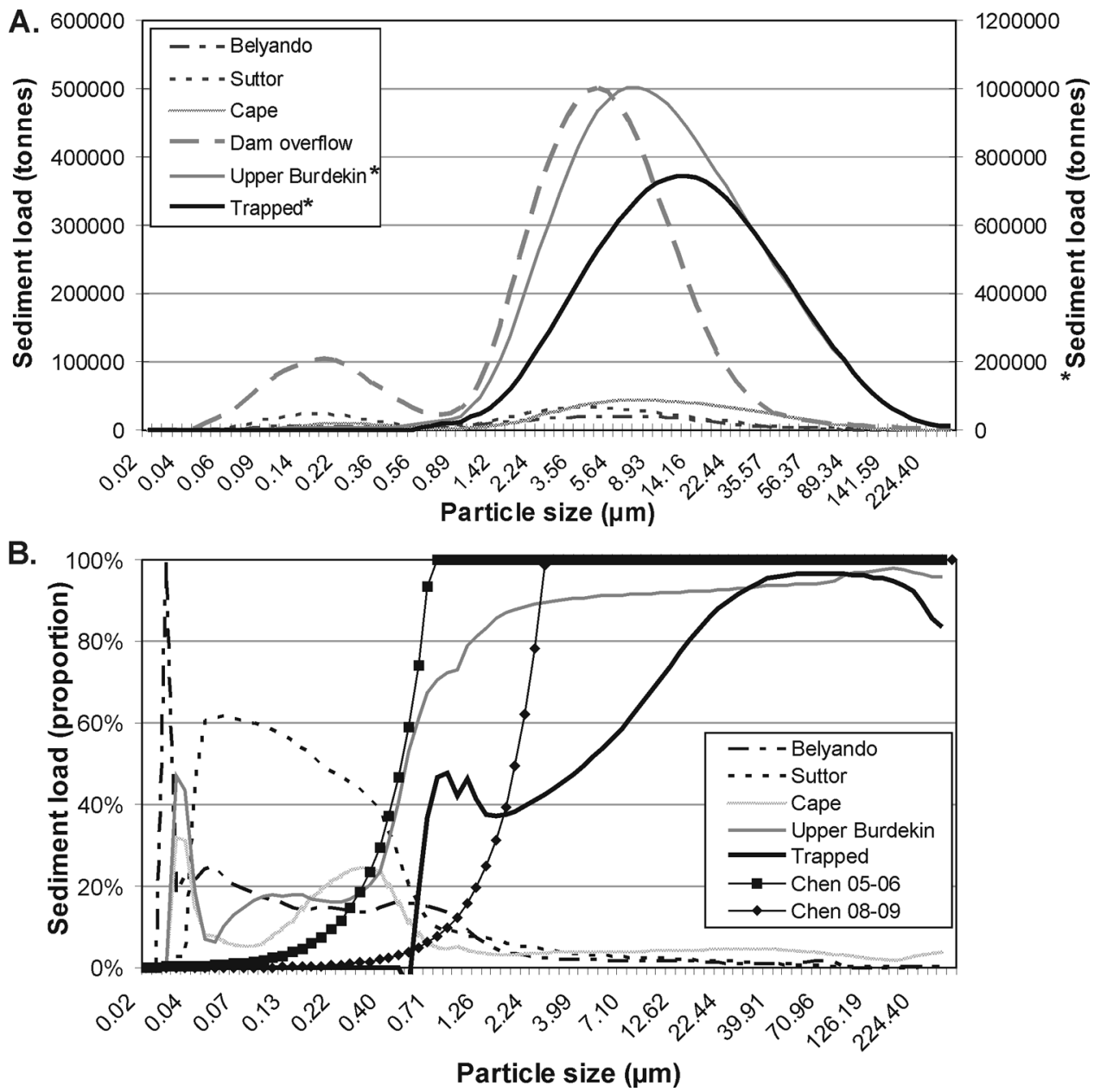

Figure 4. (A) Particle size distribution load data for the four inflow rivers, the BFD overflow and the size distribution of the sediment trapped in the reservoir over the 4 monitored years. Note that the upper Burdekin and trapped particle size distribution load have been plotted on the right $y$ axis which has a different scale to the $y$ axis on the left of the graph. (B) The proportion of particle size fractions contributed from each of the four inflow rivers and the proportion of different particle size fractions that have been trapped in the BFD reservoir are shown. Also shown is the predicted TE for particle size fractions using the Chen [1975] stratified equation.

water column fully mixed (i.e., in the case of cold, sediment-rich inflows that result in bottom density currents). The shorter travel time allows less sediment to sink to the bottom of the reservoir before the inflow passes through the storage. TSS measurements through the water column of the BFD reservoir during the large flows in the 2008/2009 water year were $\sim 100 \mathrm{mg} \mathrm{L}^{-1}$ higher in the bottom waters of the BFD (surface TSS $=250 \pm 58 \mathrm{mg} \mathrm{L}^{-1}, n=9 ; 15 \mathrm{~m}$ depth $=283 \pm 6 \mathrm{mg} \mathrm{L}^{-1}, n=3 ; 30 \mathrm{~m} \mathrm{depth}=350 \pm 30 \mathrm{mg}$ $\left.\mathrm{L}^{-1}, n=3\right)$; however, the concentrations in the surface waters still reflect the influence of the event flows and are much higher than during ambient no/low flow conditions $(<$ $10 \mathrm{mg} \mathrm{L}^{-1}$ ). The relationships developed by Brune and Churchill are likely to be more accurate for systems where the timing of the inflow means it is much more likely to enter a well-mixed (or very weakly stratified) reservoirpossibly as an underflow (i.e., colder snow melt water) leading to greater residence times than are experienced in the BFD. In contrast, the depth (range from 15 to $40 \mathrm{~m}$ ) and length (i.e., meandering) variation of the reservoir suggest changing residence times throughout the impounded water which would influence the actual residence time (and hence possibly explain departures from the predictions using Chen's method).

[34] The intraannual variability of inflows to the BFD is much higher than those from the empirical TE database (i.e., the data used to formulate the Brune and Churchill curves) which also result in much shorter residence times for the BFD. This implies that less trapping should occur than the empirical predictions and is consistent with our findings. The intraannual coefficients of variation for the reservoir stream inflows used to develop the Brune curve are considerably lower (typical range 0.06-0.95; mean 0.59: United States Geological Survey, 2012; note only data prior to the 1954 water year were used to reflect the data presented by Brune) than the rivers of the GBR watershed (range 0.65-1.5; mean 1.1: State of Queensland, 2010). In fact, the Burdekin River has one of the larger intraannual coefficients of variation (1.3) and also a relatively high interannual CV (1.1). Given the Brune, Churchill 
and Chen equations specify the use of "annual" flow data, the TE of reservoirs that experience higher intraannual inflows are likely to be overestimated by these methods.

[35] Another possible mechanism why the Brune and Churchill methods overestimate TE could be that the incoming sediments to the BFD are relatively finer and sink more slowly than those upon which the empirical relationships were based. Unfortunately particle size data are unavailable for the USA reservoirs to draw direct comparisons with the Burdekin data set. However, Chen's [1975] analysis showed that the Churchill curves for "local silt" and "upstream" sediments predict trapping for the very fine/fine silt fraction $(4-16 \mu \mathrm{m})$ while the Brune curve covers both the very fine/fine silt and coarse/medium clay $(1-16 \mu \mathrm{m})$ fractions. This analysis suggests that both the Brune and Churchill curves should predict trapping for the Burdekin data if particle size was the main influence on trapping (peak particle size of $4.5 \mu \mathrm{m}$ for overflow sediments and $7.1 \mu \mathrm{m}$ for the inflow sediments in normally distributed plots: Figure 4A). Indeed, the TE data for the BFD falls outside of Brune's envelope curves (Figure 3A) that reflect the trapping of finer and coarser sediments, respectively [see Chen, 1975; Verstraeten and Poesen, 2000].

[36] Since the measured dam TE data for the BFD plot well outside of the Brune curve envelopes (Figure 3A) and also well off the Churchill curve (Figure 3B), the lack of fit of our data to these empirical relationships is less influenced by particle size than flow variability and stratification. Ward [1980] showed that the Brune curve overestimated the TE for reservoirs on highly variable watersheds in Zimbabwe where the inflow sediments contained a coarser fraction $(9 \%-19 \%$ sand) than the particle size distribution of the BFD inflow waters and of the bottom sediments ( $\sim 6 \%$ sand). Interestingly, Chen's equation for stratified reservoirs reliably predicts the change in particle size TE for the finer fractions $(0.02-2.0 \mu \mathrm{m})$ when it is applied to the 2005/2006 and 2008/2009 flow data (i.e., the range of flows over the monitoring program) (Figure 4B); however, the equation does not accurately predict trapping for the coarser particles $(2.0-30 \mu \mathrm{m})$.

[37] Our modifications to the Brune and Churchill equations account for the more variable residence times in the BFD by calculating the daily TEs and weighting the daily inflow volumes to calculate the annual (or seasonal) sediment trapping. While the TE data used to develop the Brune curve were based on "period of record" ranging from $0.75-72$ years $($ mean $=17.2$ years, median $=10.2$ years), subsequent studies suggest that this relationship should only be used to predict "long-term" TEs [i.e., it is not suitable for single events, Verstraeten and Poesen, 2000]. We note, to our knowledge, no study has specified the length of record required for the optimal application of the Brune curve. In contrast, the Churchill curve was developed using quarterly (i.e., 3 monthly) TE data and Borland [1971] showed that this relationship could be applied to accurately predict trapping over both shorter (as short as 5 days) and longer (as long as 20 years) periods. Indeed, Espinosa-Villegas and Schnoor [2009] showed that the Churchill equation accurately predicted trapping over a 33 year period for the Coralville Reservoir, Iowa; we note that the particle size fraction ranges reported for clay, silt, and sand for this reservoir are comparable to the inflow sediments to the BFD.

[38] While our modifications to the Brune and Churchill equations better predicted the annual TEs of the BFD (within or just outside confidence intervals), only the modified Churchill equation accurately predicted trapping over the 5 year study period. Most previous studies [e.g., Borland, 1971; Trimble and Bube, 1990; Verstraeten and Poesen, 2000; Espinosa-Villegas and Schnoor, 2009] favor the Churchill curve as it incorporates the effective residence time (flow velocity plus residence time) compared to the Brune curve which is a function of residence time only. Hence, the modified Churchill equation is likely to have a wider application to predict trapping for a range of periods (from single events to decades) and account for a greater range of inflow variability. For the BFD, our modified Churchill equation provides accurate TE estimates when the period of dam overflow is considered exclusively. The only water year where the method is outside the uncertainty bounds coincides with the extreme 2008/2009 discharge from the upper Burdekin River. This method under-predicted trapping which likely reflects the relatively coarser material (and much larger sediment load) that was delivered from this event (i.e., sediment $>30 \mu \mathrm{m}$ : Figure 5).

[39] We tested our modified Churchill and Brune equations on previous TE studies where daily flow data are available including the Coralville Reservoir [Espinosa-Villegas and Schnoor, 2009], the Corpus Christi Reservoir, the Imperial Dam [Brune, 1953] and Hales Bar [Churchill, 1948], USA (Figure 6; Tables S7 and S8 in the supporting information). The modified Churchill equation underestimates TEs for the Coralville Reservoir, Iowa where the trapping predicted over the whole 33 year period $(70.2 \%)$ is lower than the measured $(80.3 \%)$ and predicted $(79.1 \%)$ trapping using the standard Churchill equation [EspinosaVillegas and Schnoor, 2009]. However, the operation of the Coralville Reservoir (designed for flood protection) may strongly influence these trapping estimates and explain why the modified Churchill equation and other standard techniques (i.e., Dendy (69.3\%), Brune (53.7\%), Heinemann $(63.5 \%)$, and Brown (64.9\%)), have underestimated sediment trapping over this period [data analysis presented in Espinosa-Villegas and Schnoor, 2009]. Observations of the inflow and outflow data for the Coralville Reservoir show that, during certain flood events, the outflow peaks precede the inflows and hence suggest that waters were released from the reservoir prior to the event inflows reaching the impoundment. In these cases, the dam should trap more sediment than if it was operated as a "normally ponded" reservoir.

[40] For the other reservoirs examined, both the standard and modified Brune and Churchill equations could not accurately predict TEs for the Corpus Christi Reservoir or for Imperial Dam. Interestingly, the standard Churchill equation overpredicted sediment TEs for the Corpus Christi Reservoir over the two periods (1934-1942 and 19421948) while the modified Churchill equation under-predicted trapping over these same periods. Only the standard Brune equation accurately predicted trapping for one of the periods (1934-1942; Table S8 in supporting information). Unfortunately, annual TE data for the Corpus Christi Reservoir are not available which may have provided better 


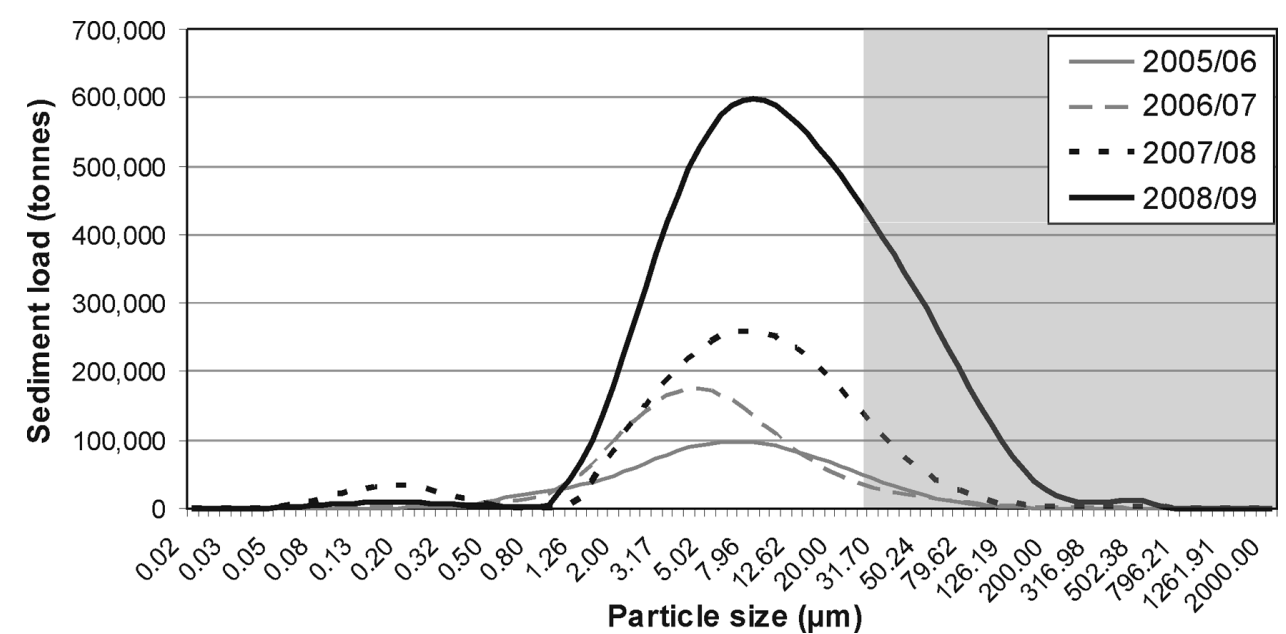

Figure 5. Particle size load data over the 2005/2006, 2006/2007, 2007/2008, and 2008/2009 water years. The shaded area shows the greater proportion of sediments that were above $30 \mu \mathrm{m}$ during the extreme flows of the 2008/2009 water year which may explain why the Churchill equation underestimated TE for that year.
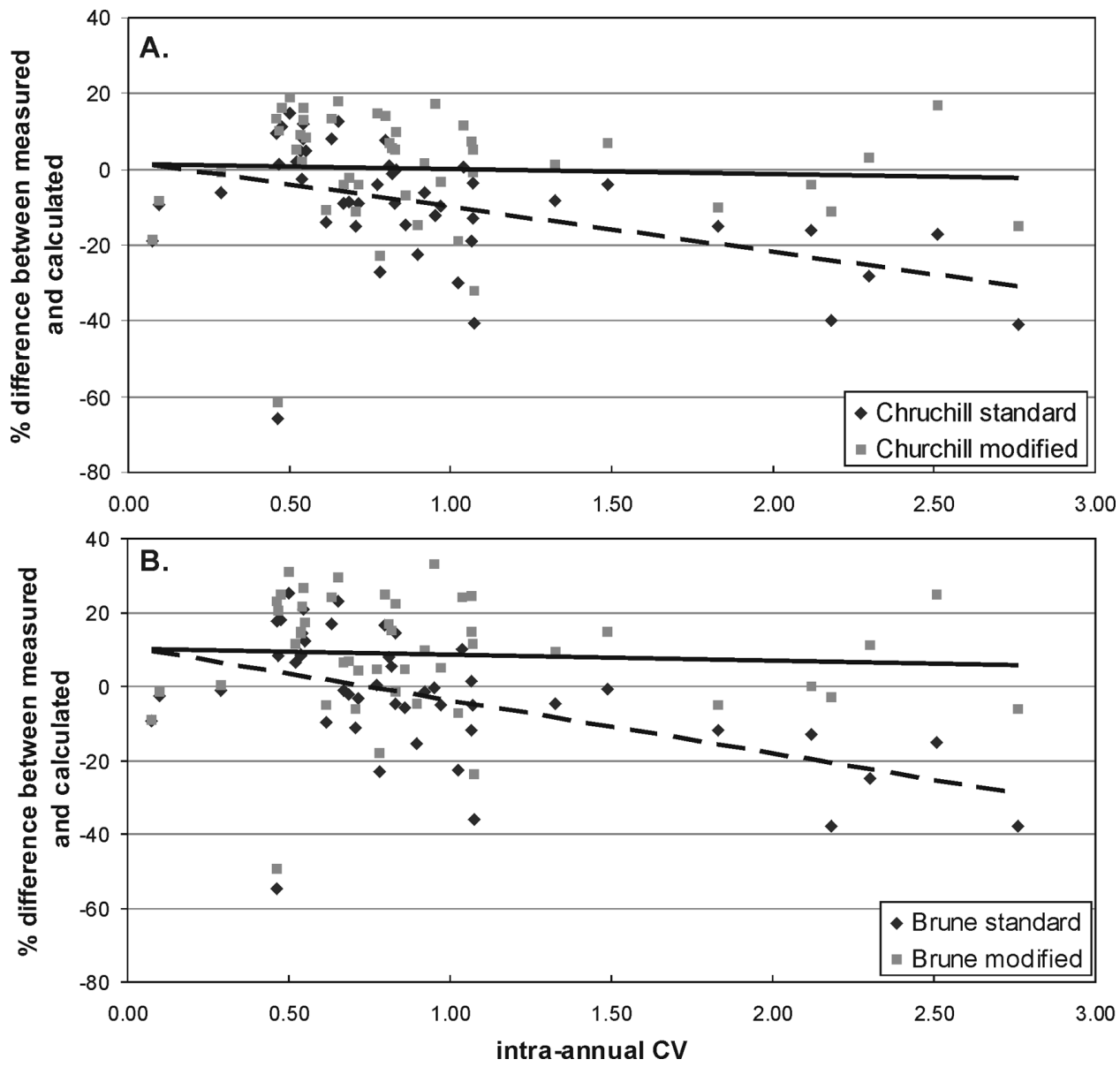

Figure 6. Plot of the differences in measured and calculated TEs for the standard and modified (A) Churchill and (B) Brune equations against the intraannual CV. The solid line is the line of best fit for the data using the modified Churchill and Brune equations and the dotted line is the line of best fit for the standard Churchill and Brune equations. 
insights to examine the performance of these methods over individual years.

[41] Similarly, TE data for individual years are not available for the Imperial Dam Reservoir which limits our interpretation of these data. The Imperial Dam is situated on the Colorado River which is highly regulated with several upstream reservoirs and has a very low intraannual CV $(\leq$ 0.10). Indeed, this low CV explains the little difference (generally $<1 \%$ ) in the TEs predicted between the standard and modified techniques (Table S8 in supporting information). Both the standard and modified Brune equations accurately predicted trapping for the 1938-1942 period, although both overestimated trapping for 1943-1947. The standard and modified Churchill equations overestimated trapping for both periods. In this case, the Churchill curve for "fine silt discharged from an upstream reservoir" may be more appropriate to apply for this reservoir given the presence of several dams upstream of this site.

[42] For the Hales Bar Reservoir, the modified Churchill equation accurately predicted (values within $5 \%$ of the measured trapping) TEs for 12 of the 17 time periods examined compared to the standard technique which only predicted 6 of the 17 periods (Table S8 in supporting information). In comparison the standard and modified Brune equations accurately predicted trapping for 10 of 17 and 11 of 17 time periods, respectively. Given that the Hales Bar data were originally used to construct the Churchill curve for "local silt", we suggest that our modified Churchill equation generally improves trapping predictions compared to the standard technique and can be applied across a wider range of reservoirs. Indeed, the lines of best fit for all the TE data show that the modified Churchill and Brune methods provide greater predictability (i.e., the percentage difference between the measured and calculated trapping remains around $0 \%$ ) across the range of intraannual coefficients of variation for the inflows (Figure 6). This result confirms that the modified equations better account for flow variability and show considerable promise to predict TEs of reservoirs across a wider range of locations. Our analysis shows that the modified Churchill equation cannot accurately predict TEs for all individual years or for dams that have certain operational protocols (e.g., flood mitigation), although it is likely to perform as well or better than the standard method. Indeed, the TE data for the BFD plot randomly along the Brune and Churchill curves when the modified equations are applied (Figure 3 ) reflecting the line of best fit in accordance with how the curves were originally developed.

[43] Physically based numerical modeling techniques can provide more accurate estimates of TE and using this approach it is possible to directly estimate the effects of sinking, particle aggregation, and diffusive transport on sediment dynamics [Casamitjana and Schladow, 1993]. Indeed, by the time a proposed reservoir enters the environmental impact assessment stage, it is likely that $2 \mathrm{D}$ or $3 \mathrm{D}$ hydrodynamic models will be employed to provide the best possible understanding of a dam's expected performance which consider various operational scenarios. However, the data requirements for reservoir hydrodynamic modeling may be excessive when the research objective requires coupling of such a model with large spatially distributed models of catchment erosion that simulate periods of decades.
In comparison, the use of the modified Churchill equation can provide a rapid and relatively accurate assessment of reservoir sediment trapping which only relies on the availability of daily inflow data.

\section{Conclusions}

[44] A 5 year sediment TE study of the BFD, Australia shows that the classic Brune and Churchill empirical relationships overestimate TEs in this reservoir located in the tropics. This is most likely due to the reduction in effective residence time caused by highly variable intraannual inflows as well as the reservoir stratification characteristics (i.e., timing of inflows). When the Churchill equation was modified to account for this intraannual variability by weighting daily TEs with corresponding daily inflow volumes, the TE predictions were within confidence intervals for four of the five years as well as for the total sediment trapped over the 5 year monitoring period (when the period of overflow was considered exclusively). This simple modification shows promise to predict TEs of reservoirs that receive highly variable intraannual inflows as well as for the less variable streams of the USA but requires further testing at other locations. We caution that the particle size distribution of inflow sediments may affect this relationship particularly when they are skewed towards a finer or coarser fraction. The very fine suspended sediment fraction $(<5 \mu \mathrm{m})$ largely passes over the Burdekin Falls Dam spillway and is predominantly sourced from the upper Burdekin and Suttor Rivers. The management of this fraction is important for the export of sediment to the Great Barrier Reef lagoon [e.g., Bainbridge et al., 2012].

[45] Acknowledgments. We are extremely grateful to Tony Bailey and Gary Caddies (SunWater) who collected the samples from the Burdekin Falls Dam (BFD) overflow over the 5 water years. Peter Burger (Department of Natural Resources and Mines, Queensland) developed the Churchill equations to calculate the daily reservoir trapping for the BFD. We thank the Queensland Department of Science, Information Technology, Innovation and the Arts GBR Loads Monitoring Program who partly funded the collection and analysis of total suspended solid samples from the major tributaries of the Burdekin. The Queensland Department of Natural Resources and Mines hydrographers (in particular Morgain Sinclair, Phil Kerr and Geoff Pocock) are acknowledged for supplying the flow data over the 5 water years. We thank Raphael Wüst (School of Earth and Environmental Sciences, James Cook University) for performing the particle size analysis. We acknowledge the efforts of the TropWATER laboratory staff for analysing the TSS samples. This research was supported by (1) the Australian Government's Marine and Tropical Sciences Research Facility, implemented in North Queensland by the Reef and Rainforest Research Centre Ltd., (2) North Queensland Dry Tropics and (3) the Australian Government's Caring for our Country Reef Rescue Research and Development Program grant to PMK. We are grateful to Peter Hairsine (CSIRO) who provided comments on an earlier draft of this manuscript. The comments of Greg Morris, James Syvitski and four anonymous reviewers greatly improved the manuscript.

\section{References}

Amos, K. J., J. Alexander, A. Horn, G. D. Pocock, and C. R. Fielding (2004), Supply limited sediment transport in a high-discharge event of the tropical Burdekin River, North Queensland, Australia, Sedimentology, 51, 145-162.

Bainbridge, Z. T., E. Wolanski, J. G. Álvarez-Romero, S. E. Lewis, and J. E. Brodie (2012), Fine sediment and nutrient dynamics related to particle size and floc formation in a Burdekin River flood plume, Australia, Mar. Pollut. Bull., 65, 236-248.

Belperio, A. P. (1979), The combined use of was load and bed material load rating curves for the calculation of total load: An example from the Burdekin River, Australia, Catena, 6, 317-329. 


\section{LEWIS ET AL.: CALCULATING TRAPPING EFFICIENCIES OF RESERVOIRS}

Borland, W. M. (1971), Reservoir sedimentation, in River Mechanics, Vol. II, edited by H. W. Shen, pp. 29.1-29.38, Colo. State Univ., Fort Collins, Colo.

Brown, C. B. (1943), Discussion of sedimentation in reservoirs, by B. J. Witzig, Proc. Am. Soc. Civil Eng., 69, 1493-1500.

Brune, G. M. (1953), Trap efficiency of reservoirs, Trans. Am. Geophys. Union, 34, 407-418.

Bureau of Meteorology (2012) [Available at: www.bom.gov.au, accessed 22 Nov. 2012].

Camp, T. R. (1946), Sedimentation and the design of settling tanks, Trans Am. Soc. Civ. Eng., 111, 895-936.

Carroll, C., et al. (2012), A paddock to reef monitoring and modelling framework for the Great Barrier Reef: Paddock and catchment component, Mar. Pollut. Bull., 65, 136-149.

Casamitjana, X., and G. Schladow (1993), Vertical-distribution of particles in stratified lake. J. Environ. Eng., 119, 443-462.

Chen, C-N. (1975), Design of sediment retention basins, paper presented at National Symposium on Urban Hydrology and Sediment Control, Univ. of Kentucky, 18-31 July 1975.

Chudek, E., M. Joo, A. Horn, and S. McLaren (1998), Stratification behaviour of Queensland dams, Res. Sci. Cent. Water Monit. Group, Queensland Dep. of Nat. Resour., Brisbane, Australia.

Churchill, M. A. (1948), Discussion of paper by L. C. Gottschalk “Analyses and use of reservoir sedimentation data," in Federal Inter-agency Sedimentation Conference Proceedings, pp. 139-140, U.S. Geol. Surv., Denver, Colo.

Cooper, M., G. Shields, J. Faithful, and J. Zhao (2006), Using Sr/Nd isotopic ratios to define sediment sources in the Burdekin Falls Dam, Queensland, Australia, Geochim. Cosmochim. Acta, 70, A112.

Espinosa-Villegas, C. O., and J. L. Schnoor (2009), Comparison of longterm observed sediment trap efficiency with empirical equations for Coralville Reservoir, Iowa, J. Environ. Eng., 135, 518-525.

Fabricius, K. E. (2005), Effects of terrestrial runoff on the ecology of corals and coral reefs: Review and synthesis, Mar. Pollut. Bull., 50, 125-146.

Faithful, J. W., and D. J. Griffiths (2000), Turbid flow through a tropical reservoir (Lake Dalrymple, Queensland, Australia): Responses to a summer storm event, Lakes Reservoirs Res. Manage., 5, 231-247.

Heinemann, H. G. (1981), A new sediment trap efficiency curve for small reservoirs, Water Resour. Bull., 17, 825-830.

Heinemann, H. G. (1984), Reservoir trap efficiency, in Erosion and Sediment Yield: Some Methods of Measurement and Modelling, edited by R. F. Hadley and D. E. Walling, pp. 201-218, GeoBooks, Norwich.

Horowitz, A. J., K. A. Elrick, and J. J. Smith (2008), Monitoring urban impacts on suspended sediment, trace element, and nutrient fluxes within the City of Atlanta, Georgia, USA: Program design, methodological considerations, and initial results, Hydrol. Process., 22, 1473-1496.

Kroon, F. J., P. M. Kuhnert, B. L. Henderson, S. N. Wilkinson, A. KinseyHenderson, J. E. Brodie, and R. D. R. Turner (2012), River loads of suspended solids, nitrogen, phosphorus and herbicides delivered to the Great Barrier Reef lagoon, Mar. Pollut. Bull., 65, 167-181.

Kuhnert, P. M., B. L. Henderson, S. E. Lewis, Z. T. Bainbridge, S. N. Wilkinson, and J. E. Brodie (2012), Quantifying total suspended sediment export from the Burdekin River catchment using the loads regression estimator tool, Water Resour. Res., 48, W04533, doi:10.1029/ 2011WR011080.
Lewis, S. E., Z. T. Bainbridge, B. S. Sherman, J. E. Brodie, and M. Cooper (2009a), The trapping efficiency of the Burdekin Falls Dam: Estimates from a three-year monitoring program, Research Report 39 to the Marine and Tropical Sciences Research Facility, 31 p., Reef and Rainforest Res. Cent. Ltd., Cairns and Aust. Cent. for Trop. Freshwater Res. (ACTFR), Townsville.

Lewis, S. E., B. S. Sherman, Z. T. Bainbridge, J. E. Brodie, and M. Cooper (2009b), Modelling and monitoring the sediment trapping efficiency and sediment dynamics of the Burdekin Falls Dam, Queensland, Australia, in 18th World IMACS Congress and MODSIM09 International Congress on Modelling and Simulation, edited by R. S. Anderssen, R. D. Braddock, and L. T. H. Newham, pp. 4022-4028, Modell. and Simul. Soc. of Aust. and N. Z. and Int. Assoc. for Math. and Comput. in Simul. ISBN: 978-0-9758400-7-8 [Available at: http://www.mssanz.org.au/modsim09/I14/lewis.pdf].

McKergow, L. A., I. P. Prosser, A. O. Hughes, and J. Brodie (2005), Sources of sediment to the Great Barrier Reef World Heritage Area, Mar. Pollut. Bull., 51, 200-211.

Prosser, I. P., C. J. Moran, H. Lu, A. Scott, P. Rustomji, J. Stevenson, G. Priestly, C. H. Roth, and D. Post (2002), Regional patterns of erosion and sediment transport in the Burdekin River catchment, CSIRO Land and Water Tech. Rep. 5/02, CSIRO, Canberra, Australia.

Restrepo, J. D., P. Zapata, J. M. Diaz, J. Garzón-Ferreira, and C. B. Garcia (2006), Fluvial fluxes into the Caribbean Sea and their impact on coastal ecosystems: The Magdalena River, Colombia, Global Planet. Change, 50, 33-49.

State of Queensland (2012), Department of Natural Resources and Mines 'Watershed', [Available at: http://www.derm.qld.gov.au/watershed/ index.html, accessed 1 Nov. 2012].

Stuart, A., and J. K. Ord (1987), Kendall's advanced theory of statistics, Vol. 1, 5th ed., p. 325, Arnold, London.

Syvitski, J. P. M. (2003), Supply and flux of sediment along hydrological pathways: Research for the 21st century, Global Planet. Change, 39, 1-11.

Syvitski, J. P., C. J. Vörösmarty, A. J. Kettner, and P. Green (2005), Impact of humans on the flux of terrestrial sediment to the global coastal ocean, Science, 308, 376-380.

Trimble, S. W., and K. P. Bube (1990), Improved reservoir trap efficiency prediction. Environ Prof., 12, 255-272.

United States Geological Survey (2012), United States Geological Survey [Available at: http://waterdata.usgs.gov/nwis/inventory?search_criteria= state_cd\&search_criteria $=$ search_station_nm\&search_criteria $=$ site_tp_cd \&search_criteria=alt_va\&search_criteria $=$ data_type\&submitted_form $=$ introduction, accessed 1 Aug. 2012].

Verstraeten, G., and J. Poesen (2000), Estimating trap efficiency of small reservoirs and ponds: Methods and implications for the assessment of sediment yield, Prog. Phys. Geogr., 24, 219-251.

Vörösmarty, C. J., and D. Sahagian (2000), Anthropogenic disturbance of the terrestrial water cycle, BioScience, 50, 753-765.

Vörösmarty, C. J., M. Meybeck, B. Fekete, K. Sharma, P. Green, and J. P. M. Syvitski (2003), Anthropogenic sediment retention: Major global impact from registered river impoundments, Global Planet. Change, 39, 169-190.

Ward, P. R. B. (1980), Sediment transport and a reservoir siltation formula for Zimbabwe-Rhodesia, Die Siviele Ing. Suid-Afrika, 22, 9-15. 